\title{
Expression of the matrix receptor CD44v5 on chondrocytes changes with osteoarthritis: an experimental investigation in the rabbit
}

\author{
C O Tibesku, T Szuwart, S A Ocken, A Skwara, S Fuchs
}

Ann Rheum Dis 2006;65:105-108. doi: 10.1136/ard.2004.034694

\begin{abstract}
Objective: To evaluate the expression of CD44v5 on chondrocytes of hyaline cartilage during the course of osteoarthritis (OA).

Methods: In 12 white New Zealand rabbits the anterior cruciate ligament $(\mathrm{ACL})$ was resected to create an anterior instability of the knee. In 12 control rabbits only a sham operation without resection of the $\mathrm{ACL}$ was done. Four animals of each group were killed at 3,6 , and 12 weeks. The loadbearing area was evaluated histologically according to Mankin and by immunostaining for CD44v5.

Results: In the trial group, histological grades of OA showed a positive linear correlation with the time after surgery. Immunostaining showed an increased expression of CD44v5 in the control group after 3 and 6 weeks, which dropped to normal after 12 weeks. There was no difference between control and trial groups after 3 and 6 weeks, but a difference was seen after 12 weeks. A significant positive correlation between CD44v5 expression and the histological grade of $\mathrm{OA}$ was found $(r=0.314)$.

Conclusions: $A n$ in vivo increase of expression of the hyaluronan receptor CD44v5 occurs during the course of OA. Further studies are needed to evaluate whether this pattern applies to man and whether new treatment approaches might evolve from this knowledge.
\end{abstract}

\footnotetext{
A transmembrane glycoprotein, CD44, can bind extracellular human cartilage matrix components like fibronectin and collagen types I and IV. Additionally, it has a role as principal cell surface receptor for hyaluronan. ${ }^{12}$ CD44 occurs in a standard form and in several other isoforms ${ }^{3}$ as alternatively spliced variant exon encoded gene products. ${ }^{4}$ In human cartilage, $\mathrm{CD} 44 \mathrm{H}$ is expressed in chondrocytes of normal and osteoarthritic tissue. ${ }^{5}$

Previous studies have suggested a vital role for chondrocyte CD44 in cartilage homoeostasis and matrix attachment and indicated a participation of CD44v5 in the development of osteoarthritis (OA). ${ }^{6-8}$ We have evaluated the expression of the CD44 variant isoform v5 in synovial fluid, synovia, and cartilage of human late stage OA knee joints. ${ }^{67}$ However, all reports dealt with late stage human OA. Thus, little is known about the expression of CD44v5 during the course of OA.

This study was designed to evaluate $(a)$ expression of the isoform CD44v5 during the course of OA and $(b)$ possible correlations with histological findings.
}

\section{MATERIAL AND METHODS}

The experiments were performed with permission of the local government in accordance with National Institute of Health (NIH) guidelines (G49/2000). Twenty eight fully grown, female white New Zealand rabbits were used. The animals weighed a mean (SD) of 4193 (299) g at surgery and 4275 (462) g when killed.

All animals were operated on bilaterally under a single general anaesthesia and received an intramuscular depot of antibiotics (Tardomyocel) and intramuscular metamizole (Novalgin) for treatment of pain. A $3 \mathrm{~cm}$ medial paramedian skin incision and a medial parapatellar capsular incision were used. In 12 rabbits the anterior cruciate ligament (ACL) was resected (group 1). An intraoperative Lachman test was carried out to evaluate anterior instability. In 12 control rabbits only a sham operation was done (group 2). Postoperatively, all animals were allowed to move freely in their cages $(100 \mathrm{~cm} \times 70 \mathrm{~cm} \times 40 \mathrm{~cm})$. Four animals of each group were killed at 3, 6, and 12 weeks postoperatively. The four animals of group 3 did not undergo any treatment and were killed at the time of surgery of groups 1 and 2. Both distal femurs were immediately stored at $-80^{\circ} \mathrm{C}$.

Frozen tissue samples (3-5 mm thick) were thawed and fixed with $4 \%$ paraformaldehyde for 2 days. After decalcification with buffered EDTA (20\% ethylene diamine tetraacetic acid, pH 7.4) the samples were dehydrated and embedded in paraffin. Sections ( $5 \mu \mathrm{m}$ thick) were cut, mounted on poly-Llysine coated glass slides, deparaffinised in xylene, and washed three times with distilled water and then with Tris buffer $(\mathrm{pH} 7.5)$ for $3 \times 2$ minutes each. Histological changes were evaluated according to the Mankin score ${ }^{9}$ by two independent investigators who were unaware of the source of the specimens.

The sections were incubated with proteinase $\mathrm{K}$ (ready to use, DAKO, Germany) for 5 minutes, followed by a washing procedure. Endogenous peroxidase activity was quenched by treating tissue sections with $3 \% \mathrm{H}_{2} \mathrm{O}_{2}$ for 10 minutes. After washing, the sections were incubated with $3 \%$ bovine serum albumin in Tris buffer to block non-specific binding. After rinsing three times with Tris buffer the sections were next incubated with monoclonal mouse antirabbit CD44v5 (IgGl, clone VFF-18) antibodies at room temperature over night (diluted 1:400, BMS115, Bender MedSystems). The sections were washed three times with Tris buffer and then treated with antimouse IgG (DAKO Envision Systems, Germany, K4001) for 30 minutes at room temperature. To visualise antibody binding, after three washes in Tris, the staining was developed by incubation with AEC-chromogene (ready to use, DAKO, Germany) for 30 minutes, and the reaction was stopped by rinsing in distilled water. In control experiments, (a) sections were incubated without primary antibody or $(b)$ instead of primary antibody, mouse IgGl with irrelevant specificity (Aspergillus niger glucose oxidase, DAKO, Germany) was used at the same concentration.

Abbreviations: $\mathrm{ACL}$, anterior cruciate ligament; $\mathrm{OA}$, osteoarthritis 


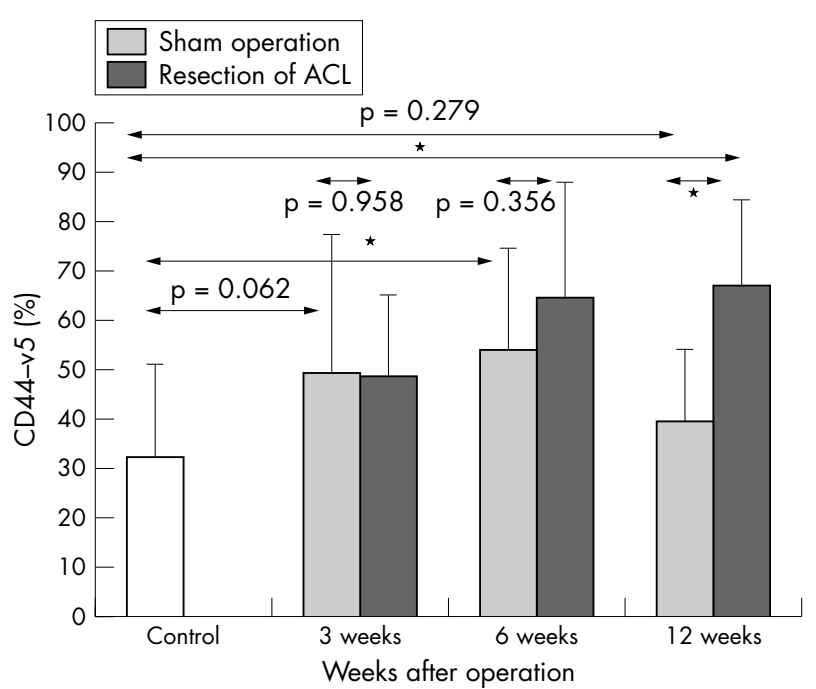

Figure 1 Development of CD44v5 expression during the time course. The percentages of $C D 44 v 5$ positive cells differed significantly between groups 1 and 2 after 12 weeks $(p<0.05)$, but not after $3(p=0.958)$ and 6 weeks $(p=0.356)$. In group 1 (resection of $A C L)$ the percentage of CD44v5 positive cells increased steadily in the time course, whereas in group 2 (sham operation) it was significantly raised after 6 weeks but decreased from 6 to 12 weeks. After 12 weeks there was no difference in the percentage of $C D 44 v 5$ positive cells between group 2 (sham operation) and the unoperated controls $(p=0.279)$, whereas the percentage of $C D 44 v 5$ positive cells was increased in group 1 (resection of $\mathrm{ACL})\left({ }^{*} \mathrm{p}>0.05\right)$.

Histological sections were photographed (CoolSnap-Pro Color A00J82025, Media Cybernetics, Silver Spring, MD, USA). The cells were counted using the Image-Pro Plus software for Windows, version 4.1 (Media Cybernetics, Silver Spring, MD, USA). The total number of chondrocytes was determined in a haematoxylin and eosin stained section and compared with the number of immunohistochemically stained cells.

Statistical analysis was performed using SPSS 11.0 (SPSS $\mathrm{GmbH}$, Munich, Germany). Student's $t$ test was used for comparison of scores, and Pearson's coefficient was calculated for correlations.

\section{RESULTS}

Two animals developed postoperative haematomas-one a superficial wound infection treated with a single shot antibiotic, and one animal a wound gap reoperated on 2 days after surgery. All four animals were included in the analysis. At the time of death, one animal of group 1 had intact ACLs and was excluded from evaluation. In total, 54 joints were evaluated.

\section{Histological grading of OA}

According to the Mankin score, group l showed a highly significant increase in the grade of OA in comparison with groups 2 and 3. In group 3 the mean (SD) grade of OA was 1.75 (1.58). In group 2 it was 3.25 (0.71) after 3 weeks, 1 (1.20) after 6 weeks, and 2.25 (1.17) after 12 weeks. In group 1 the scores were 7.25 (3.62) after 3 weeks, 8 (2.88) after 6 weeks, and 9.83 (3.06) after 12 weeks. Group 1 had significantly higher values than group 2 at every time point $(\mathrm{p}<0.01)$. The average histological grade of OA increased with the number of postoperative weeks.

\section{Immunohistochemical staining of CD44v5}

CD44v5 positive chondrocytes were found in the trial and control groups (see figs $2 \mathrm{~A}-\mathrm{F}$ ). In group 2 the mean (SD) percentage of CD44v5 positive cells was 49.1 (28.1)\% after 3 weeks, $54.1(20.4) \%$ after 6 weeks, and $39.5(14 / 7) \%$ after 12 weeks (fig 1 ). In group 1 the percentages were 48.5 (16.6)\% after 3 weeks, $64.6(23.5) \%$ after 6 weeks, and 66.9 (17.6)\% after 12 weeks. The percentages of CD44v5 positive cells differed significantly between the two groups after 12 $(p<0.05)$, but not after $3 \quad(p=0.958)$ and 6 weeks $(\mathrm{p}=0.356)$. In group 3 the mean $(\mathrm{SD})$ percentage of CD44v5 positive cells was $32.2(19.0) \%$. In group 1 the percentage of CD44v5 positive cells increased steadily with time, whereas in group 2 it was significantly raised compared with group $3 \quad(\mathrm{p}<0.05)$ after 6 weeks but decreased from 6 to 12 weeks. After 12 weeks there was no difference between groups 2 and $3(p=0.279)$, whereas the percentage of CD44v5 positive cells was increased in group 1 $(\mathrm{p}>0.05)$.

A significant correlation was found between the percentage of CD44v5 positive chondrocytes and the histological grade $(r=0.314, \mathrm{p}=0.021)$.

\section{DISCUSSION}

As far as we know, this study is the first to evaluate the expression of CD44 containing variant isoform v5 and its correlation with histological features in experimental OA.

A percentage of chondrocytes in healthy cartilage expressed CD44v5, indicating its physiological role. CD44v5 positive and CD44v5 negative chondrocytes were found in most of the specimens. This corresponds with findings of the standard isoform CD44H on human OA cartilage ${ }^{5}{ }^{10}$ and is in accordance with the detection of alternative spliced messenger RNA transcripts containing the exon 5 in OA chondrocytes. $^{510}$ In human OA, up regulated $\mathrm{CD} 44 \mathrm{H}$ expression was found in the deep zone of the cartilage. ${ }^{10}$ This finding correlates with our late stage results after 12 weeks.

The increase of CD44v5 expression with increasing OA stages suggests that it participates in the pathogenesis of OA. This is in line with the results of others, who showed that up regulated chondrocyte metabolism leads to up regulated CD44 expression in cultured bovine chondrocytes. ${ }^{11}$ Another explanation for an increased CD44v5 expression might be found in the obviously altered binding capacity compared with $\mathrm{CD} 44 \mathrm{H}$. In tumour cells a correlation of increased ectopic CD44v5-7 expression on the cell surface and an increased soluble hyaluronan binding capacity was seen. ${ }^{12}$ The authors postulated that the regulation of clustering of CD44, mediated by factors including the presence of variant exons and glycosylation, allows cells to regulate their hyaluronan binding capacities.

In a previous study on the expression of CD44v5 in synovial fluid, synovia, and cartilage of human late stage OA, we demonstrated that CD44v5 expression in cartilage and synovia seemed to correlate strongly with the histological grade of cartilage destruction. ${ }^{6}$ In the present study, we confirmed a correlation of chondrocyte CD44v5 expression and histological joint destruction, although correlation coefficients were low. Reasons for this partial correspondence might be found in different evaluation methods (percentage of patients expressing CD44v5 $v$ percentage of chondrocytes expressing CD44v5) and inclusion of healthy cartilage and early stage $\mathrm{OA}$ in the present results, in contrast with predominantly late stage OA specimens. ${ }^{6}$

In patients with rheumatoid arthritis, serum and synovial fluid sCD44v5 levels correlated with advanced stages and inflammatory activity. ${ }^{13-15}$ We found evidence that CD44v5 expression is, at least partly, influenced by inflammation, as the sham operation group showed increased expression after 6 weeks, which returned to normal after 12 weeks. 

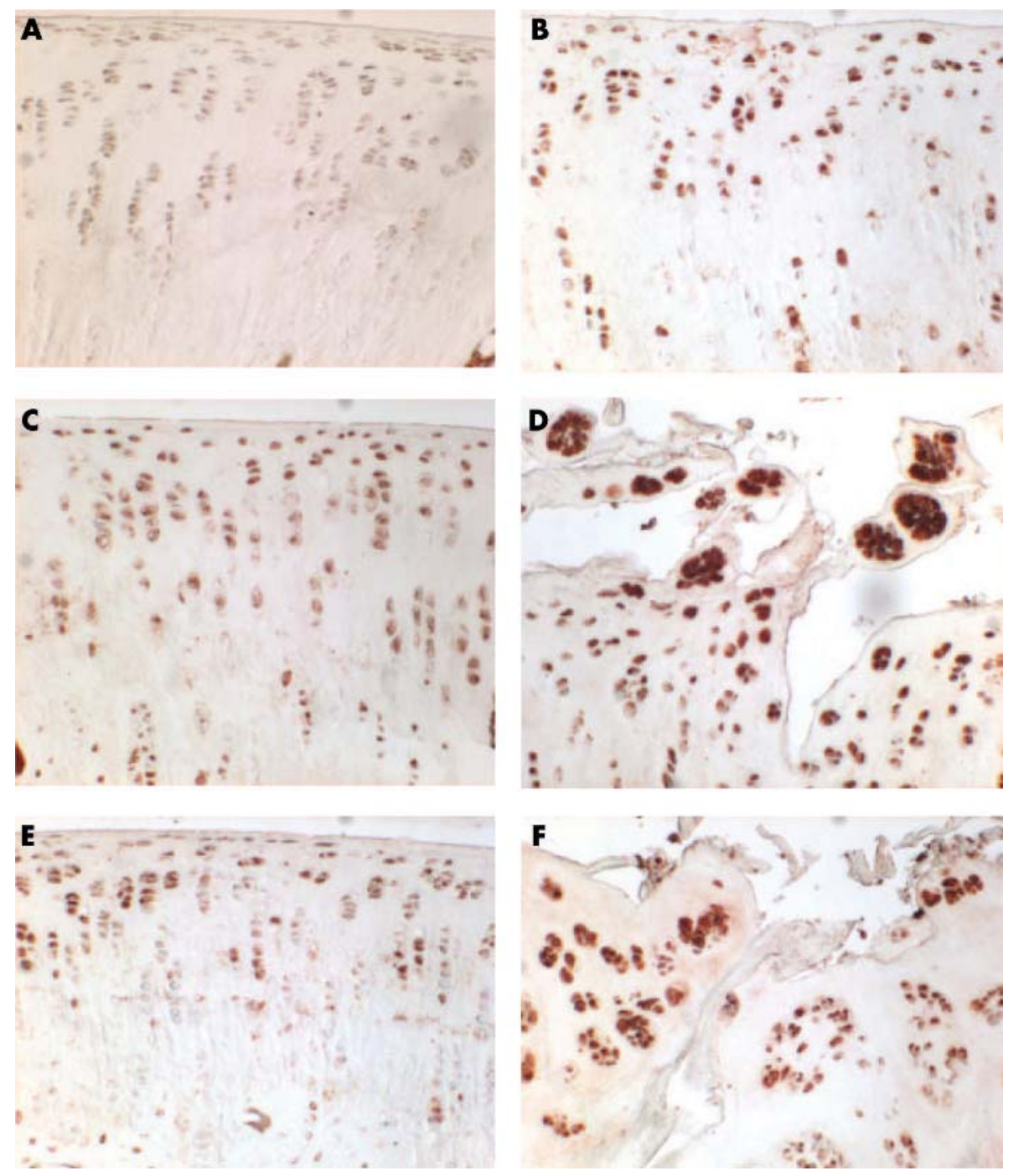

Figure 2 CD44v5 expression (A) 3 weeks after sham operation; (B) 3 weeks after ACL resection; (C) 6 weeks after sham operation; (D) 6 weeks after $A C L$ resection; $(E) 12$ weeks affer sham operation; $(F) 12$ weeks after $A C L$ resection;

In conclusion, our results show an increased expression of CD44v5 during the course of OA. Further studies are needed to evaluate $(a)$ its physiological role, $(b)$ whether CD44v5 up regulation is an underlying cause of OA or a repair response, (c) whether this applies to humans, and (d) whether new treatment approaches might evolve from this knowledge.

\section{ACKNOWLEDGEMENTS}

We thank Ms S Kupich for expert technical assistance.

\section{Authors' affiliations}

C O Tibesku, S A Ocken, A Skwara, S Fuchs, Department of Orthopaedics, University Hospital Muenster, Germany T Szuwart, Clinical Anatomy, Institute of Anatomy, Westfalian Wilhelms University Muenster, Germany

None of the authors received any financial support for this study and no author has any financial interest in the topic of the study.

Correspondence to: Dr C O Tibesku, Klinik für Orthopädie und Rheumatologie, Universitätsklinikum Giessen und Marburg, Standort Marburg, Baldingerstrasse, 35043 Marburg, Germany; carsten@ tibesku.de

Accepted 16 May 2005

\section{REFERENCES}

1 Aruffo A, Stamenkovic I, Melnick M, Underhill CB, Seed B. CD44 is the principal cell surface receptor for hyaluronate. Cell 1990;61:1303-13.

2 Culty M, Miyake K, Kincade PW, Sikorski E, Butcher EC, Underhill C, et al. The hyaluronate receptor is a member of the CD44 (H-CAM) family of cell surface glycoproteins. J Cell Biol 1990;111:2765-74.

3 Bajorath J. Molecular organization, structural features, and ligand binding characteristics of CD44, a highly variable cell surface glycoprotein with multiple functions. Proteins 2000;39:103-11.

4 Hale LP, Haynes BF, McCachren SS. Expression of CD44 variants in human inflammatory synovitis. J Clin Immunol 1995; 15:300-11.

5 Salter DM, Godolphin JL, Gourlay MS, Lawson MF, Hughes DE, Dunne E. Analysis of human articular chondrocyte CD44 isoform expression and function in health and disease. J Pathol 1996;179:396-402.

6 Fuchs S, Dankbar B, Wildenau G, Goetz W, Lohmann CH, Tibesku CO. Expression of the CD44 variant isoform 5 in the human osteoarthritic knee joint: correlation with radiological, histomorphological, and biochemical parameters. J Orthop Res 2004;22:774-80.

7 Fuchs S, Rolauffs B, Arndt S, Tibesku CO, Prehm P. CD44H and the isoforms CD44v5 and CD44v6 in the synovial fluid of the osteoarthritic human knee joint. Osteoarthritis Cartilage 2003; 11:839-44.

8 Knudson W, Loeser RF. CD44 and integrin matrix receptors participate in cartilage homeostasis. Cell Mol Life Sci 2002;59:36-44.

9 Mankin HJ, Dorfman H, Lippiello L, Zarins A. Biochemical and metabolic abnormalities in articular cartilage from osteo-arthritic human hips. II. Correlation of morphology with biochemical and metabolic data. J Bone Joint Surg Am 1971;53:523-37. 
10 Ostergaard K, Salter DM, Andersen CB, Petersen J, Bendtzen K. CD44 expression is up-regulated in the deep zone of osteoarthritic cartilage from human femoral heads. Histopathology 1997;31:451-9.

11 Chow G, Knudson CB, Homandberg G, Knudson W. Increased expression of CD44 in bovine articular chondrocytes by catabolic cellular mediators. J Biol Chem 1995;270:27734-41.

12 Sleeman J, Rudy W, Hofmann M, Moll J, Herrlich P, Ponta H. Regulated clustering of variant CD44 proteins increases their hyaluronate binding capacity. J Cell Biol 1996; 135:1139-50.
13 Feyertag J, Haberhauer G, Skoumal M, Kittl EM, Bauer K, Dunky A. [Serum soluble CD44 isoform variant 5 level in patients with seropositive rheumatoid arthritis treated with cyclosporin A]. Acta Med Austriaca 2000;27:156-9.

14 Haberhaver G, Kittl EM. Soluble CD44 isoform variant-5 (sCD44v5): a new serum marker in rheumatoid arthritis? J Rheumatol 1998;25:1442-4

15 Kittl EM, Haberhauer G, Ruckser R, Selleny S, Rech-Weichselbraun I, Hinterberger $W$, et al. Serum levels of soluble CD44 variant isoforms are elevated in rheumatoid arthritis. Rheumatol Int 1997;16:181-6.

\section{Clinical Evidence-Call for contributors}

Clinical Evidence is a regularly updated evidence-based journal available worldwide both as a paper version and on the internet. Clinical Evidence needs to recruit a number of new contributors. Contributors are healthcare professionals or epidemiologists with experience in evidence-based medicine and the ability to write in a concise and structured way.

Areas for which we are currently seeking contributors:

- Pregnancy and childbirth

- Endocrine disorders

- Palliative care

- Tropical diseases

We are also looking for contributors for existing topics. For full details on what these topics are please visit www.clinicalevidence.com/ceweb/contribute/index.jsp

However, we are always looking for others, so do not let this list discourage you.

Being a contributor involves:

- Selecting from a validated, screened search (performed by in-house Information Specialists) epidemiologically sound studies for inclusion.

- Documenting your decisions about which studies to include on an inclusion and exclusion form, which we keep on file.

- Writing the text to a highly structured template (about 1500-3000 words), using evidence from the final studies chosen, within 8-10 weeks of receiving the literature search.

- Working with Clinical Evidence editors to ensure that the final text meets epidemiological and style standards.

- Updating the text every 12 months using any new, sound evidence that becomes available. The Clinical Evidence in-house team will conduct the searches for contributors; your task is simply to filter out high quality studies and incorporate them in the existing text.

If you would like to become a contributor for Clinical Evidence or require more information about what this involves please send your contact details and a copy of your CV, clearly stating the clinical area you are interested in, to CECommissioning@bmigroup.com.

\section{Call for peer reviewers}

Clinical Evidence also needs to recruit a number of new peer reviewers specifically with an interest in the clinical areas stated above, and also others related to general practice. Peer reviewers are healthcare professionals or epidemiologists with experience in evidence-based medicine. As a peer reviewer you would be asked for your views on the clinical relevance, validity, and accessibility of specific topics within the journal, and their usefulness to the intended audience (international generalists and healthcare professionals, possibly with limited statistical knowledge). Topics are usually 1500-3000 words in length and we would ask you to review between 2-5 topics per year. The peer review process takes place throughout the year, and out turnaround time for each review is ideally 10-14 days.

If you are interested in becoming a peer reviewer for Clinical Evidence, please complete the peer review questionnaire at www.clinicalevidence.com/ceweb/contribute/peerreviewer.jsp 